\title{
Article \\ Similarity Calculation Method for Infield and Outfield Low-Temperature Environmental Tests of Aircraft Sealing Rubber Material
}

\author{
Yongjie Zhang *, Renzhong Guo, Yunhui Zhang and Ke Liang * \\ School of Aeronautics, Northwestern Polytechnical University, Xi'an 710072, China; \\ guorz@mail.nwpu.edu.cn (R.G.); zyh001@mail.nwpu.edu.cn (Y.Z.) \\ * Correspondence: zyj19191@nwpu.edu.cn (Y.Z.); k.liang@nwpu.edu.cn (K.L.)
}

check for updates

Citation: Zhang, Y.; Guo, R.; Zhang, Y.; Liang, K. Similarity Calculation Method for Infield and Outfield Low-Temperature Environmental Tests of Aircraft Sealing Rubber Material. Appl. Sci. 2021, 11, 2148. https://doi.org/10.3390/app11052148

Academic Editor: Ricardo Branco

Received: 19 January 2021

Accepted: 23 February 2021

Published: 28 February 2021

Publisher's Note: MDPI stays neutral with regard to jurisdictional claims in published maps and institutional affiliations.

Copyright: (c) 2021 by the authors. Licensee MDPI, Basel, Switzerland. This article is an open access article distributed under the terms and conditions of the Creative Commons Attribution (CC BY) license (https:// creativecommons.org/licenses/by/ $4.0 /)$.

\begin{abstract}
This study aims to accurately simulate the outfield low-temperature environment for the key components of aircraft in the parking state, using the infield low-temperature environmental test chamber, when there is a difference between the infield and outfield environments; and, moreover, reveal the similarity between the influences of the infield and outfield low-temperature environments on the elastic properties of the rubber sealing materials for aircraft. Two kinds of rubber materials were examined in the infield and outfield — the tensile springback test and the isobaric elongation testand the measured data of low-temperature steady-state response (elastic property) were obtained under the typical temperature of -40 to $10^{\circ} \mathrm{C}$, finding that there is difference of elastic property between the infield and outfield environment. Three fitting methods were then used to describe the relationship between elasticity and temperature. In view of the difference of the elastic response of the typical rubber sealing materials to the low-temperature infield and outfield, a similarity calculation method of infield and outfield low-temperature tests was proposed, based on the translation and scaling transformation of the similarity curve. The outfield test data verify that the method proposed has high goodness of fit, and it is feasible and generalizable in the low-temperature performance testing and research of rubber materials and components.
\end{abstract}

Keywords: sealing rubber; low-temperature behavior; elasticity; infield and outfield; similarity calculation method

\section{Introduction}

At present, about $20 \%$ of the world's flight accidents are caused by meteorological factors. In low-temperature environments, aircraft and spacecraft are prone to ice accumulation, improper sealing, hydraulic failure, and electronic equipment failure. The performance of the sealing rubber can be easily affected by low-temperature environments, thus affecting aircraft safety. In 1986, for example, the U.S. space shuttle "Challenger" crashed due to sealing failure of the O-ring of the solid rocket motor in a low-temperature environment. It is thus necessary to carry out low-temperature environmental chamber tests, or infield tests, to understand the performance of the aircraft sealing rubber in the design and verification stages.

In the study of the low-temperature properties of the rubber materials, the temperature volume relationship of the rubber is usually studied to obtain the low-temperature properties of the rubber [1]. Common methods such as standardized compression set measurement and simplified low temperature compression or tensile properties measurement [2-4]. With the decrease in temperature, the toughness of the carboxyl terminated nitrile butadiene rubber (CTBN) decreases with the glass transmission of the rubber [5]. The mechanical properties of the silicone rubber at low-temperature are related to glass transition temperature, low-temperature crystallization, macromolecular structure and cohesive energy, but the tensile strength and elongation at break decrease at low-temperature [6]. 
The elastic modulus of fluorosilicone rubber also decreases rapidly at low temperature [7]. Isoprene rubber will further reduce its elasticity and toughness due to crystallization under low-temperature for a long time [8]. In a low-temperature environment, the decrease in elasticity caused by vitrification of commonly used vulcanized rubber will occur rapidly, which will affect the sealing performance and mechanical properties of its material products [9]. At low-temperature, the decrease in the stiffness of rubber products is related to the decrease in elasticity and the increase in hardness, which will affect the shock absorption and noise reduction effect of rubber products at low temperature [10]. At present, there are some methods to predict and simulate rubber stiffness at low temperature, but it depends on the known properties of rubber at low-temperature [11].

There are some research results on the influencing factors of low temperature rubber properties. For example, the sensitivity of rubber to low temperature is different when the large deformation condition and loading rate are different, and when the thermal hyperelastic model is used for theoretical analysis of the materials, it can only achieve better simulation of the rubber low temperature performance in a certain temperature range [12]. The addition of cis-1,4-polybutadiene rubber as modifier can control the lowtemperature crystallization process of natural rubber, thus improving the shear modulus and bonding properties of the rubber at low temperature [13]. Sodium bisulfate in natural rubber can also effectively affect the crystallization of macromolecules in a low temperature environment, so as to improve the low temperature performance of natural rubber [14]. Formulation is the most important factor affecting the low temperature properties of rubber, especially the glass transition temperature [15]. Vulcanization systems and plasticizers also have a high influence on the low temperature properties of rubber (such as styrene butadiene rubber) [16]. The effect of natural rubber crystallization on the shear modulus is approximately independent of the crosslinking density and crystallization temperature. When the crystal is regarded as a thread network, the effect of crystallization can be well predicted, so as to achieve the inhibition of the low-temperature crystallization of the rubber [17]. In addition, the aging of the rubber materials and nanofillers will also have a certain impact on its low temperature performance [18]. For Nitrite Butadiene Rubber(NBR), the barrier effects of lubricating oil, oxygen consumption and penetration also affect its performance [19].

In the study of the low-temperature properties of materials and the performance of rubber components, the above researchers all used a temperature test chamber, but did not carry out the corresponding research on the consistency of the material properties in the outfield environment (which means the practical application environment of the materials and components) at the corresponding temperature. Whether the influence of the external environment on the low temperature properties of the rubber materials is consistent with that of the internal environment has not been considered.

Rubber materials were selected in a low-temperature environmental test. In lowtemperature environments, the macromolecular chains in rubber gradually freeze, and low-temperature hardening occurs. At this time, the typical properties of materials, such as elasticity, are quite different from those of materials in normal working temperature. Low-temperature hardening will lead to the sealing and hydraulic failure of typical rubber products such as sealing strip and hydraulic seal, thus affecting the safety of the aircraft.

In this study, two kinds of rubber sealing materials (nitrile rubber and butyl rubber) for aircraft were selected for the infield and outfield tensile springback tests and isobaric elongation tests. The measured data of the infield and outfield low-temperature steadystate response (elastic property) were obtained under the typical low-temperature parking condition of -40 to $10^{\circ} \mathrm{C}$. Three fitting methods-polynomial, exponential and Fourier fittings-were used to describe the elasticity curve of typical rubber sealing materials, while the temperature and the goodness of fit of the curve obtained by the three fitting methods were compared. In view of the difference of the elastic response of the rubber sealing materials in the infield and outfield low-temperature environments, the similarity of the elastic properties of the two rubber materials infield and outfield were studied by 
translating the internal field curve. A similarity calculation method of the infield and outfield low-temperature tests was then proposed based on the translation and scaling transformation of the similar curve. In this way, the outfield-derived curve is obtained from the infield curve. Through four-point interpolation, the outfield interpolation curve is obtained for comparison. The derived curve, interpolation curve and outfield fitting curve were compared in terms of the goodness of fit. The results show that the similarity calculation method has a small error of goodness of fit. The derived curve of the two materials and the corresponding outfield fitting curve were also compared, revealing close goodness of fit with different fitting methods. Therefore, the similarity calculation method demonstrates feasibility and popularization, applicable to other rubber materials and different fitting methods.

\section{Infield and Outfield Environmental Tests of Rubber Materials}

\subsection{Effect of Temperature on Rubber Materials}

Rubber is a nonlinear elastic material, characterized by material nonlinearity and geometric nonlinearity. Its elastic modulus varies with strain. With the change of the temperature and the strain rate, rubber materials can take on three states: viscous flow, rubber, and glass states. From low temperature to high temperature, the states of rubber are glass state, glass transition state, elastic state, viscous flow transition state and viscous flow state. For the low temperature range we studied, the main states of rubber include the glass state, the glass transition state and the elastic state. When the rubber material is in the glass state, the macromolecular chain is frozen and can hardly move; only the bond length and bond angle of the atoms in the chain change, as well as the movement of some side bases, branches and small chain segments; the relaxation time of the chain segment movement is almost infinite. In this state, rubber can hardly deform under stress. Rubber exhibits Hooker elastic behavior with a high modulus. In the glass transition state the, molecular chains begin to thaw, the macromolecular chains become active, the chain segments begin to move, and the rubber materials begin to exhibit damping properties. Because of the large amount of friction between the molecules, mechanical energy can be transformed into heat energy through friction, so the chain motion is irreversible. In this state, rubber can deform a little, but the deformation cannot be the same as in the normal environment, showing viscous behaviors. With the increase in temperature, the movement of the molecular chain becomes more flexible, and its conformation changes from the curling state to the stretching state. However, the movement of the molecular chain is still dominated by segment motion, not by the movement of the whole molecular chain. There is no slip of the molecular chain, and the deformation is reversible.

\subsection{Test Scheme}

This study designed two kinds of tests to examine the low-temperature properties of rubber materials according to their low-temperature hardening and viscous properties in the glass transition zone, based on the national standard of static mechanical tests [20,21], the low-temperature performance of the rubber, and the test conditions of outfield test. The two tests are the low-temperature tensile springback test and the low-temperature isobaric elongation test.

In the tensile springback test, the specimen is stretched to a certain length for $10 \mathrm{~min}$, at room temperature $\left(25^{\circ} \mathrm{C}\right)$, then moved to a windless, no direct sunlight, low-temperature environment for $15 \mathrm{~min}$. After the specimen is hardened in the low-temperature environment, the clamp is loosened to make the hardened specimen rebound naturally for $15 \mathrm{~min}$, and the length after hardening and rebounding at different temperatures is measured. In the isobaric elongation test, after the specimen is hardened in the windless, no direct sunlight, low-temperature environment, the specimen is subjected to the same load by hanging the weight, and the length of the specimen after hardening (15 $\mathrm{min}$ ) and loading (15 min) under different temperatures is measured. The parameters, such as tensile length, loading and experimental time, are determined by the pre-experiment. The tensile length 
and loading weight the specimen under tension to facilitate measurement and reduce the excessive crystallization caused by loading [12,17]. The shorter time after the specimen is frozen and hardened is selected as the experimental time to capture the short temperature stability period of the external temperature. After stretching, the length of the measuring section is $80 \mathrm{~mm}$, which is twice the original length, and the loading weight is $1.5 \mathrm{~kg}$.

\subsection{Test Equipment and Specimens}

In order to test the elastic properties of the rubber in infield and outfield tests, an experimental framework was used to measure the elongation and retraction properties of the elastic materials in both the natural high and low-temperature environments and the environmental test chamber, as shown in Figure 1 . The frame size is $250 \times 400 \times 600$ (depth $\times$ width $\times$ height). In the tests, 3 specimens in one group were loaded and stretched by the clamp mounted on the experimental frame, and a few parts were replaced for the stretching springback and isobaric stretching tests under different internal and external environments. The clamp is a stainless steel jaw clamp controlled by hexagon screw (the size is $18 \mathrm{~mm} \times 38 \mathrm{~mm} \times 41 \mathrm{~mm}$, the maximum opening is $3.5 \mathrm{~mm}$, the upper limit load is $500 \mathrm{~N}$, and the weight is about $75 \mathrm{~g}$ ).

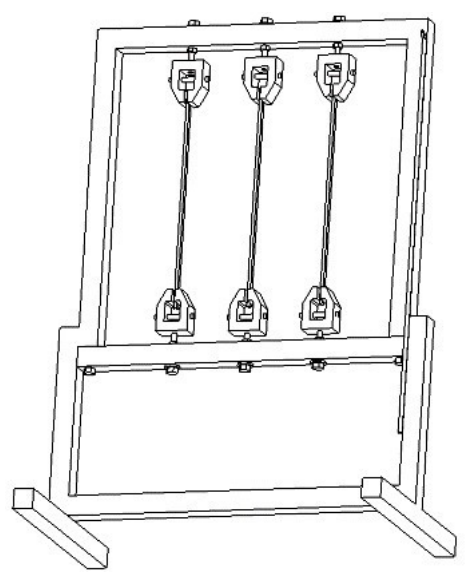

(a)

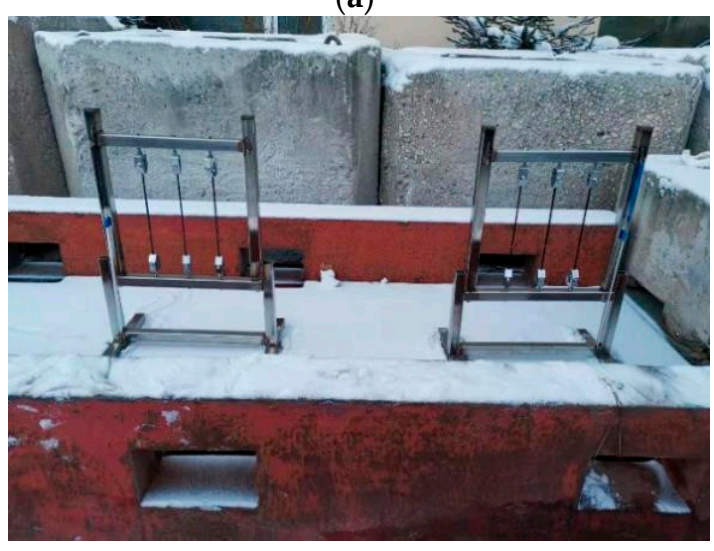

(c)

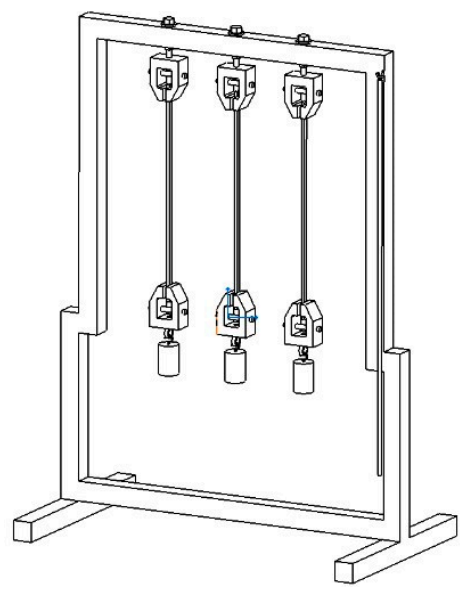

(b)

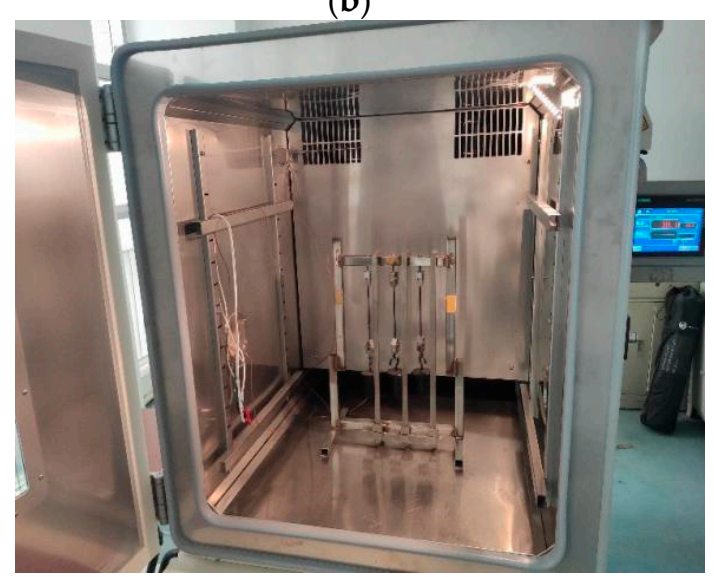

(d)

Figure 1. Test devices. (a) Tensile springback test (b) Isobaric elongation test (c) Tensile springback test device (d) Isobaric elongation test device.

The infield test used the high and low temperature environmental test chamber, as shown in Figure 2. The no-load cooling rate of the test chamber is $\geq 2{ }^{\circ} \mathrm{C} / \mathrm{min}$, the temperature uniformity is $\leq \pm 0.5^{\circ} \mathrm{C}$, and the temperature deviation is $\leq \pm 0.4{ }^{\circ} \mathrm{C}$. 


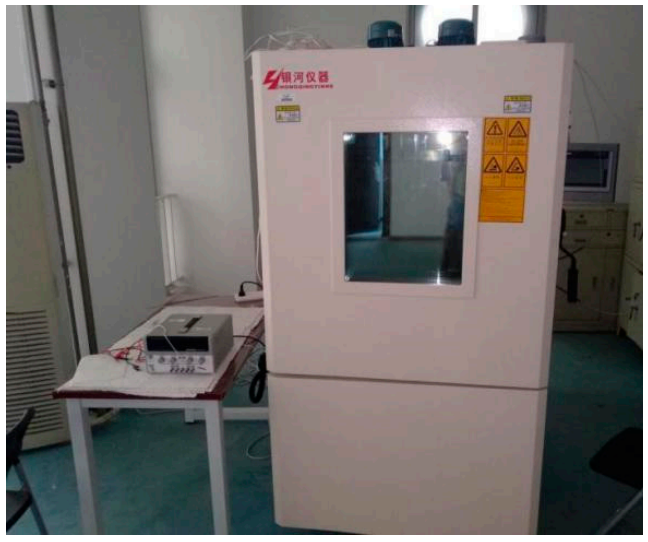

(a)

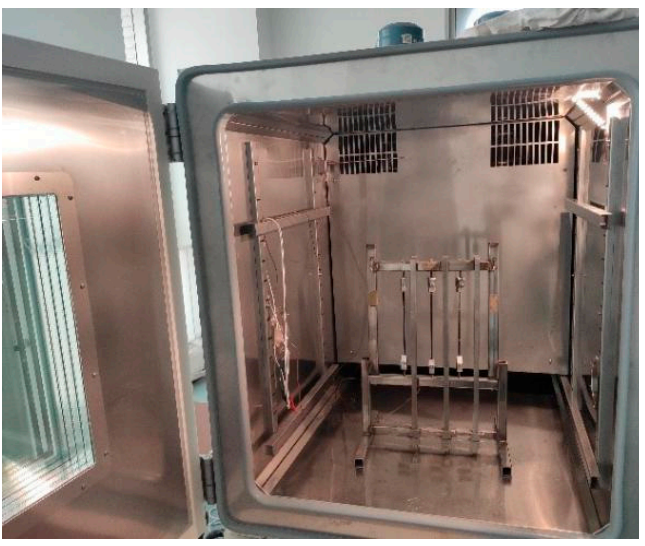

(b)

Figure 2. Environmental test chamber. (a) Device appearance (b) Experimental area.

The materials selected in this test were a kind of nitrile rubber 5860 (material A) used in helicopters and a kind of butyl rubber (material B) vulcanized from a cenway 552 compound, with the size being $100 \mathrm{~mm} \times 5 \mathrm{~mm} \times 3 \mathrm{~mm}$, as shown in Figure 3 .

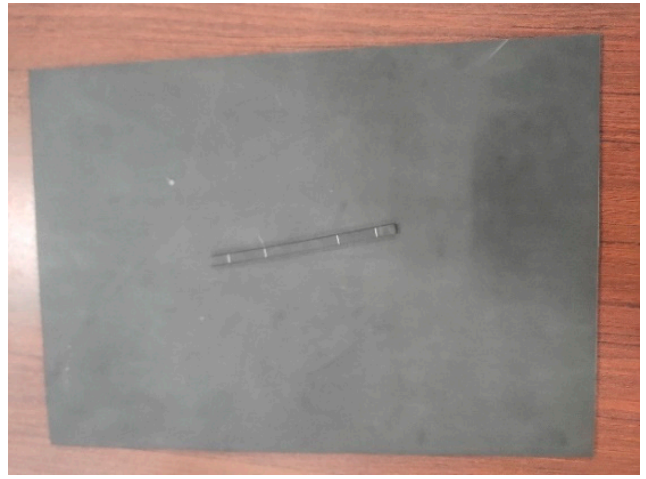

(a)

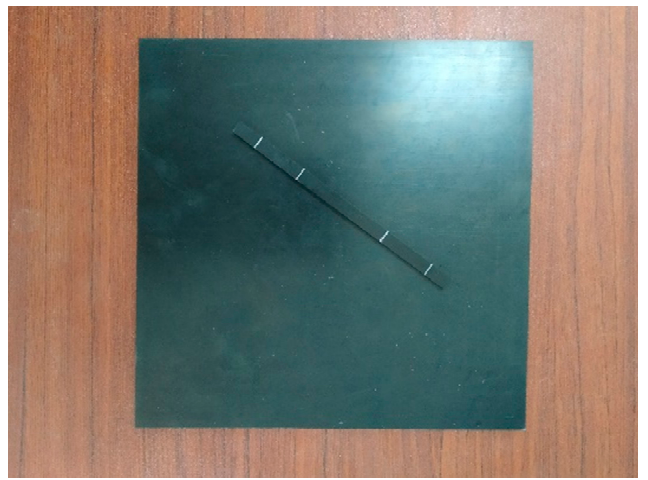

(b)

Figure 3. Rubber specimens. (a) Material A (b) Material B.

\subsection{Test Process and Results}

The typical low-temperature parking temperature range of the aircraft is -40 to $10^{\circ} \mathrm{C}$. In the infield and outfield environments for this temperature range, the tensile springback tests and isobaric elongation tests are carried out on the two kinds of specimens. The pretest was carried out before the test to compare the elongation and springback of the specimens at different low-temperature environment times. When the experimental scheme is freezing for $15 \mathrm{~min}$ (or more) plus loading for $15 \mathrm{~min}$ (or more), the experimental data is basically stable. The appropriate test time is determined to ensure the stability of loading and unloading state and reduce the fluctuation range of field temperature. In the outfield experiment, we should grasp the required environmental temperature range to carry out the experiment, and there are a small number of temperature points greater than $10^{\circ} \mathrm{C}$ after the average- - these data are also adopted.

The specimens were pretreated: heated for $45 \mathrm{~min}$ at $50^{\circ} \mathrm{C}$ and held for $24 \mathrm{~h}$ to ensure that they were in the same state. The sample test shows that the properties of the sample have no change after pretreatment.

In the outfield tests, the thermometer was used for temperature measurement, and this outfield thermometer was calibrated and checked by the calibrated temperature test chamber before. When the ambient temperature measured by the thermometer is close to the temperature to be tested $\left(<0.5^{\circ} \mathrm{C}\right)$, the experiment is started. Considering the instability of the external temperature in the outfield test, the temperature of the tests was measured 
three times, and the average value was taken as the test temperature when the temperature fluctuation was no more than $1^{\circ} \mathrm{C}$.

The process of infield and outfield tests is shown in Figure 4.

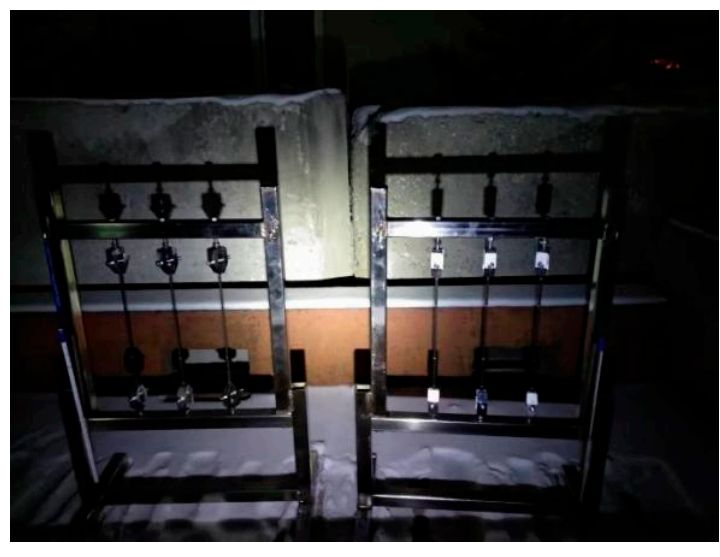

(a)

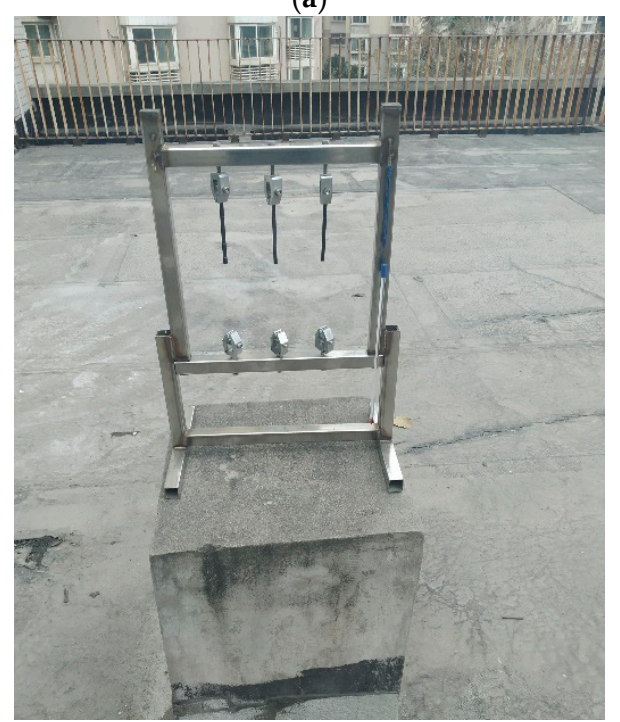

(c)

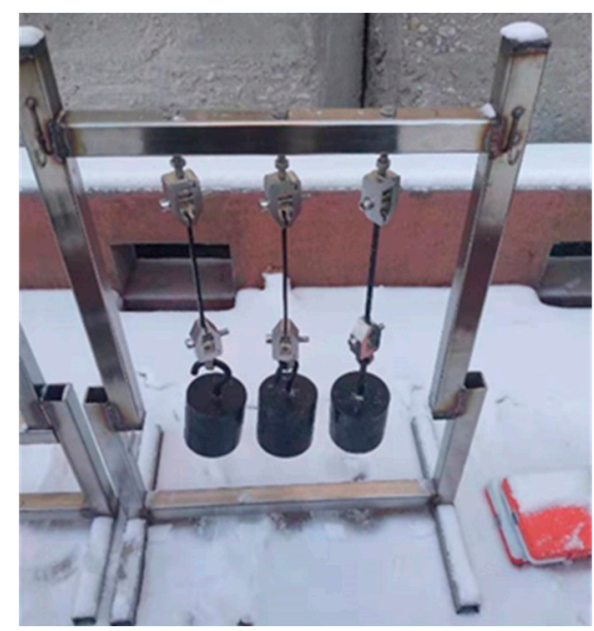

(b)

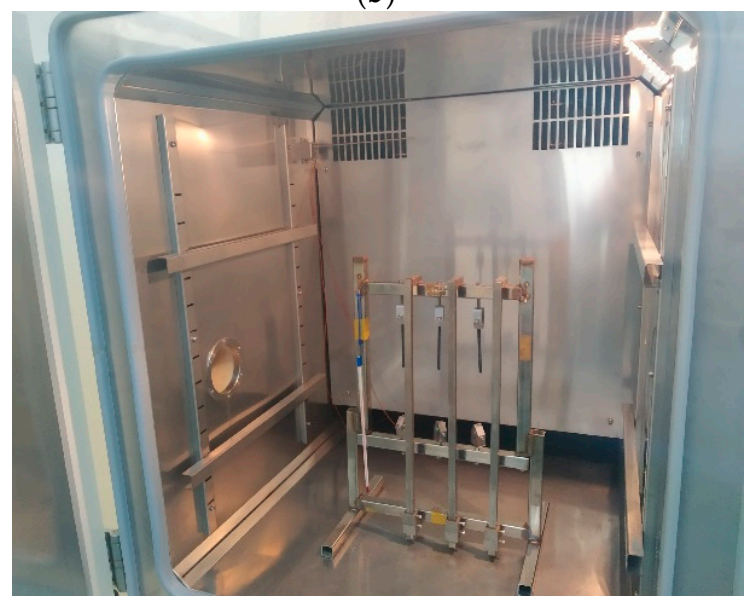

(d)

Figure 4. Infield and outfield tests. (a) Tensile springback test outfield at night (b) Isobaric elongation test outfield (c) Tensile springback test outfield (with clamp loosed) (d) Tensile springback test infield (with clamp loosed).

When the specimen is subjected to constant pressure tensile test, a small change in the cross-sectional area may lead to a large range of tensile length. In order to solve the experimental error caused by the cross-sectional area error, the tensile test was carried out at room temperature $\left(25^{\circ} \mathrm{C}\right)$ with the same loading weight before the low-temperature test. The results of the low-temperature tensile test and the normal temperature tensile test were compared to eliminate the error caused by the cross-sectional area. In the data processing of the tensile test, the concept of low temperature elongation is adopted. The low-temperature elongation is the ratio of the low-temperature tensile test length to the room temperature tensile test length of a specimen. The processing method of the tensile test data is shown in the Figure 5. Because the measured value of the rebound test specimen is the rebound length, which has nothing to do with the cross-sectional area of the specimen, only the tensile test data are equivalently processed. 


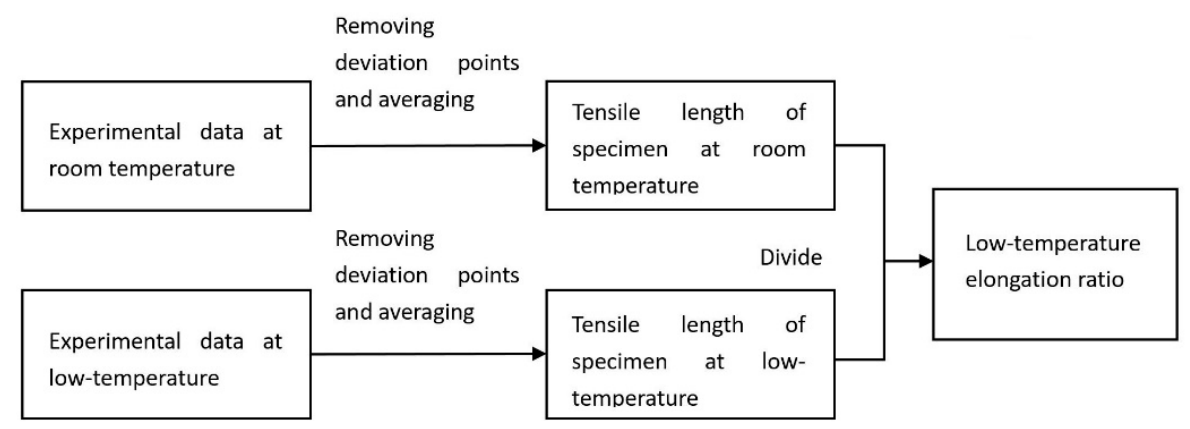

Figure 5. Data processing method of tensile test.

Through the test, the steady-state response data of the elastic properties of the two typical sealing rubber materials at the low-temperature infield and outfield were obtained. The results are shown in Figure 6. The test results show that material A and material $B$ harden at low temperatures in both the infield and outfield environments; that is, the elasticity of the material becomes worse at low temperatures, and both rubbers are in the glass transition region at $-40{ }^{\circ} \mathrm{C}$, but they do not reach their glass transition temperature. For material $\mathrm{A}$, there is a difference between the infield and outfield elasticity, and the elasticity is worse in the infield low-temperature environment. For material $\mathrm{B}$, there is no significant difference between the infield and outfield low-temperature elasticity.

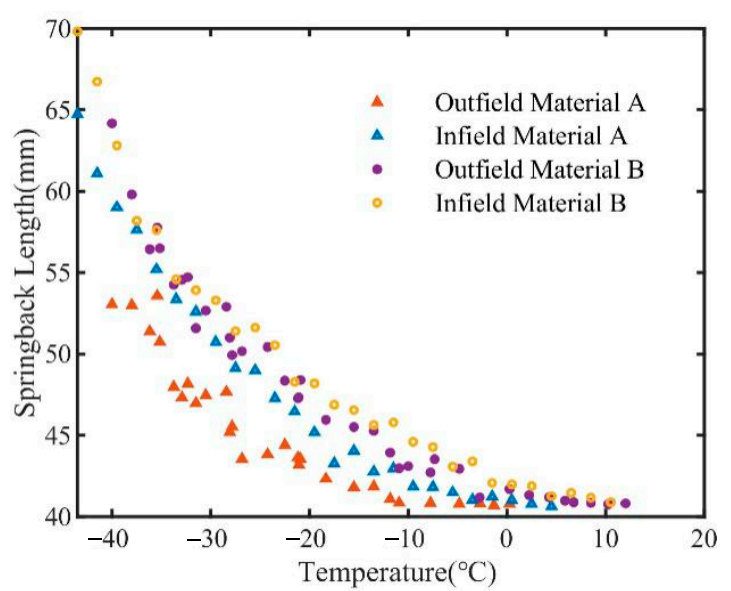

(a)

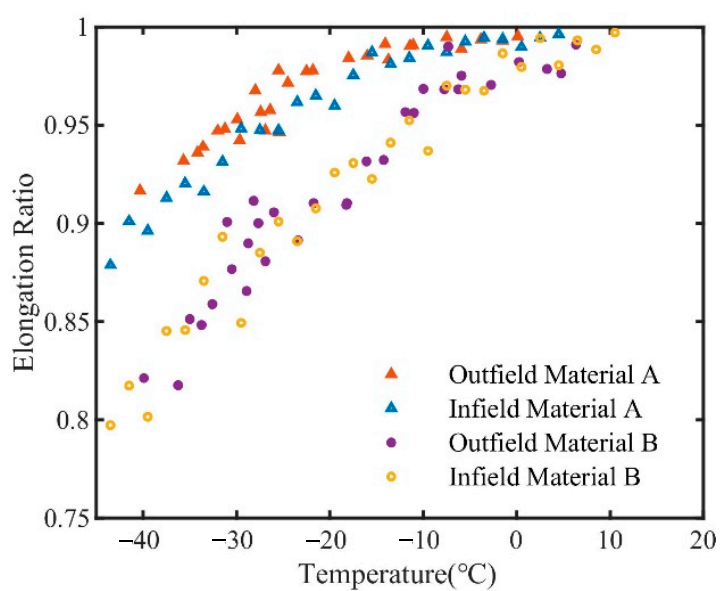

(b)

Figure 6. Test results. (a) Springback test results. (b) Elongation test results.

From the relationship between rubber properties and low temperature properties, it can be inferred that when the temperature continues to decrease, the springback and tensile length of the material will continue to decrease until the temperature reaches the glass transition temperature of the material, and the material will no longer rebound and stretch. When the temperature is higher than the experimental temperature, the material will continue to show complete rebound and similar tensile load at room temperature.

Moreover, the elastic changes in the glass transition zone at low temperature are different due to the different degrees of the immobilization and thawing of the molecular chains of rubber materials under the influence of low temperature. The reason is as follows. During the low temperature test, the low temperature environment in the test chamber is relatively stable, but the outdoor temperature test is carried out according to the outdoor low temperature environment. The outdoor test will be carried out in the daytime or at night, so the sunshine, wind speed, air convection and other factors may affect the elastic properties of rubber. The sensitivity of the two rubber materials to these factors in the 
outfield is also different, resulting in different elastic properties in the infield and outfield low temperature environment.

In the infield test, due to the sensitivity of the material A rubber to outfield factors such as sunshine and wind speed, the temperature of the material may be higher than that measured in the environment. At this time, the glass transition of the rubber material is lower than that of the material infield at the same temperature, the rubber macromolecular chain is more active, and the friction between the molecules is smaller. Compared with the infield test, the deformation degree of material $\mathrm{A}$ is larger under stress, and the rebound condition is better. However, material B is relatively insensitive to the influence of outfield factors, so the difference between the infield and outfield tests is inconspicuous.

\section{Data Analysis of Similarity Calculation Method for Infield and Outfield Environmental Tests}

\subsection{Data Analysis and Fitting of Environmental Tests}

From the test data shown in Figure 6, it can be seen that the hardening degree of the two kinds of rubber in the vitrification transformation zone is significantly related to temperature. That is, the lower the temperature, the more obvious the hardening. The difference between the infield tests and the outfield tests is also demonstrated. At the same temperature, the springback and elongation of the infield tests are different from those of the outfield test, with the springback and elongation of the infield tests being smaller. In addition, at the same temperature, the hardening of the two materials is more obvious in the infield test environment. Based on a genetic algorithm [22], three curve fitting models were then used to fit the data of the outfield environmental tests: namely, the polynomial, exponential, and Fourier fitting models.

The polynomial models for the curves are given by,

$$
y=\sum_{i=1}^{n+1} p_{i} x^{n+1-i}
$$

where $n+1$ is the order of the polynomial, $n$ is the degree of the polynomial, and $1 \leq n \leq 9$. The order gives the number of coefficients to be fit, and the degree gives the highest power of the predictor variable. The main advantages of the polynomial fits include reasonable flexibility for data that is not too complicated, and they are linear, which means the fitting process is simple [23].

The one-term and two-term exponential model as given by,

$$
y=a e^{b x}+c e^{d x}
$$

Exponential fits are often used when the rate of change of a quantity is proportional to the initial amount of the quantity $[20,21]$.

The Fourier series is a sum of sine and cosine functions that describes a periodic signal. It is represented in either the trigonometric form or the exponential form [21].

$$
y=a_{0}+\sum_{i=1}^{n} a_{i} \cos (i w x)+b_{i} \sin (i w x)
$$

where $a_{0}$ models a constant (intercept) term in the data and is associated with the $i=0$ cosine term, $w$ is the fundamental frequency of the signal, $n$ is the number of terms (harmonics) in the series, and $1 \leq n \leq 8$.

These three models are commonly used in curve fitting, and can balance the smoothness of the curve and the accuracy of the data fitting.

The goodness of fit $R^{2}$ was used to evaluate the fitting error of the constitutive model, which is defined as

$$
R^{2}=1-S S_{e r r} / S S_{t o t}
$$




$$
\begin{aligned}
S S_{\text {tot }} & =\sum_{i=1}^{N}\left(P_{i}-\bar{P}\right)^{2} \\
S S_{\text {err }} & =\sum_{i=1}^{N}\left(\hat{P}_{i}-\bar{P}_{i}\right)^{2}
\end{aligned}
$$

where $S S_{\text {err }}$ denotes the residual error, $S S_{\text {tot }}$ deviation, $P_{i}$ test value, $\bar{P}$ average value of $P_{i}, \hat{P}_{i}$ model fitting value, and $N$ the number of test data points participating in the fitting. The larger the $R^{2}$, the higher the goodness of fit and the smaller the error.

The form of polynomial fitting is

$$
f_{1}(T)=p_{1} T^{3}+p_{2} T^{2}+p_{3} T+p_{4}
$$

The form of exponential fitting is

$$
f_{2}(T)=a e^{(-b T)}+c
$$

The form of Fourier fitting is

$$
f_{3}(T)=a_{0}+a_{1} \cos (T w)+b_{1} \sin (T w)
$$

The fitting curve parameters of the three fitting methods for the infield and outfield test data are shown in Tables 1-3, and the goodness of fit is shown in Table 4 and Figure 7. The fitting curves of the springback and elongation tests of the two materials based on the three fitting methods are shown in Figure 8.

Table 1. Polynomial fitting coefficient.

\begin{tabular}{ccccc}
\hline Coefficients & $p 1$ & $p 2$ & $p 3$ & $p 4$ \\
\hline Outfield springback & -0.0001176 & 0.005580 & 0.06518 & 40.92 \\
\hline Outfield elongation & $-2.011 \times 10^{-7}$ & $-6.544 \times 10^{-5}$ & $9.171 \times 10^{-5}$ & 0.9945 \\
\hline Infield springback & -0.0002816 & -0.003121 & -0.1933 & 42.79 \\
\hline Infield elongation & $1.094 \times 10^{-8}$ & $-4.374 \times 10^{-5}$ & 0.002189 & 0.979 \\
\hline
\end{tabular}

Table 2. Exponential fitting coefficient.

\begin{tabular}{cccc}
\hline Coefficients & $\boldsymbol{a}$ & $\boldsymbol{b}$ & $\boldsymbol{c}$ \\
\hline Outfield springback & 2.461 & 0.05436 & 38.28 \\
\hline Outfield elongation & -0.02057 & 0.0435 & 1.016 \\
\hline Infield springback & 2.562 & 0.05555 & 39.90 \\
\hline Infield elongation & -0.09687 & 0.02415 & 1.075 \\
\hline
\end{tabular}

Table 3. Fourier fitting coefficient.

\begin{tabular}{ccccc}
\hline Coefficients & $\boldsymbol{a 0}$ & $\boldsymbol{a 1}$ & $\boldsymbol{b 1}$ & $\boldsymbol{w}$ \\
\hline Outfield springback & $1.672 \times 10^{9}$ & $-1.672 \times 10^{9}$ & 6494 & $3.861 \times 10^{-6}$ \\
\hline Outfield elongation & -0.7670 & 0.2274 & 0.004408 & 0.02331 \\
\hline Infield springback & $3.451 \times 10^{8}$ & $-3.451 \times 10^{8}$ & $-1.204 \times 10^{4}$ & $7.918 \times 10^{-6}$ \\
\hline Infield elongation & $-2.538 \times 10^{5}$ & $2.538 \times 10^{5}$ & -117.0 & $-1.868 \times 10^{-5}$ \\
\hline
\end{tabular}


Table 4. The goodness of fit.

\begin{tabular}{ccccc}
\hline Fitting Type & A Springback & B Springback & A Elongation & B Elongation \\
\hline $\begin{array}{c}\text { Polynomial fitting } \\
\text { outfield } R^{2}\end{array}$ & 0.9497 & 0.9823 & 0.9255 & 0.9348 \\
\hline $\begin{array}{c}\text { Polynomial fitting } \\
\text { infield } R^{2}\end{array}$ & 0.9965 & 0.988 & 0.9823 & 0.9669 \\
\hline $\begin{array}{c}\text { Exponential fitting } \\
\text { outfield } R^{2}\end{array}$ & 0.9471 & 0.9840 & 0.9157 & 0.9331 \\
\hline $\begin{array}{c}\text { Exponential fitting } \\
\text { infield } R^{2}\end{array}$ & 0.9956 & 0.9889 & 0.9782 & 0.9667 \\
\hline $\begin{array}{c}\text { Fourier fitting } \\
\text { outfield } R^{2}\end{array}$ & 0.9533 & 0.9855 & 0.928 & 0.9418 \\
\hline $\begin{array}{c}\text { Fourier fitting } \\
\text { infield } R^{2}\end{array}$ & 0.9966 & 0.9944 & 0.9823 & 0.9684 \\
\hline
\end{tabular}

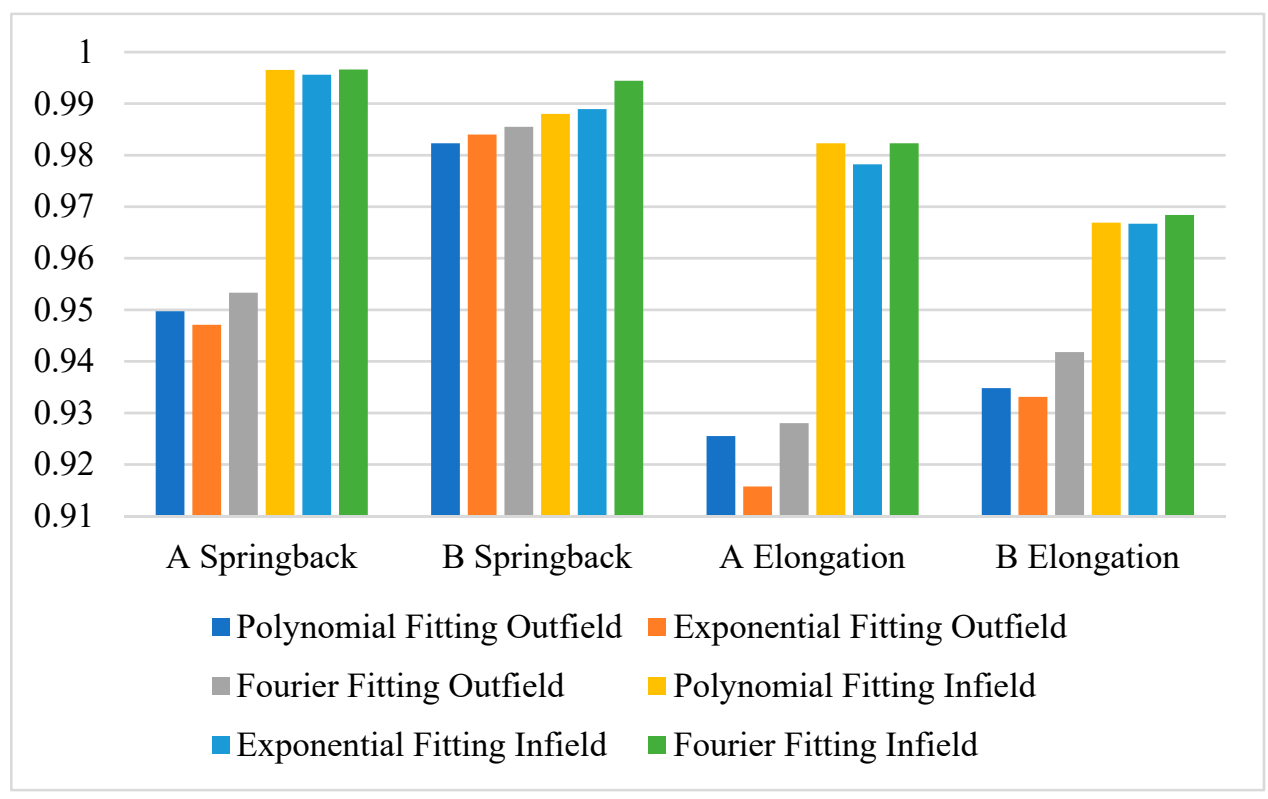

Figure 7. The goodness of fit.

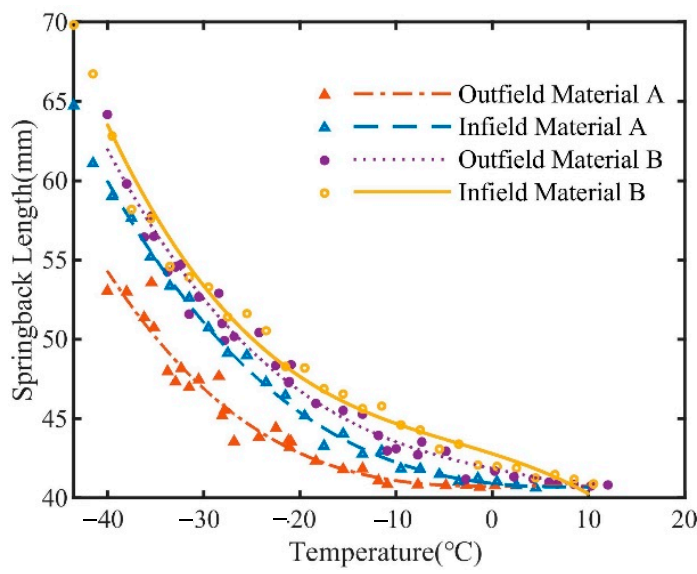

(a)

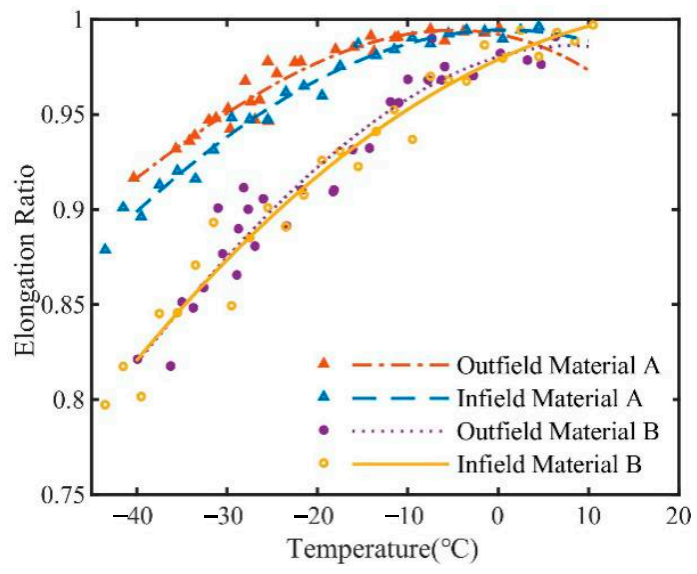

(b)

Figure 8. Cont. 


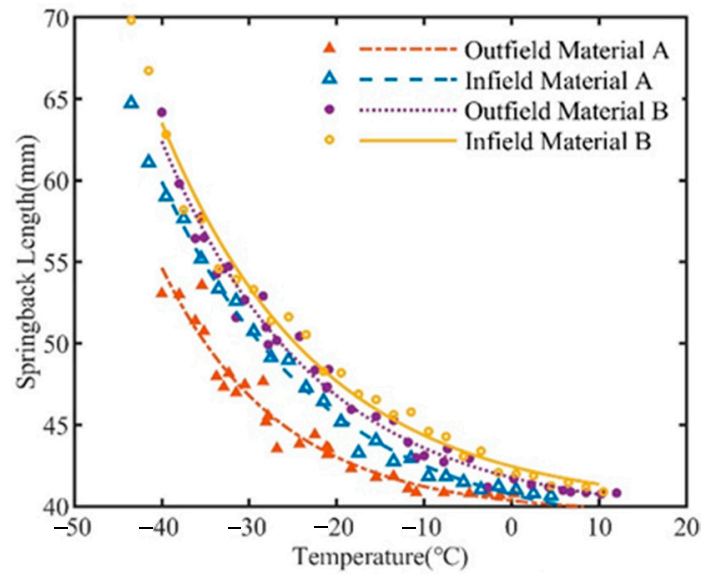

(c)

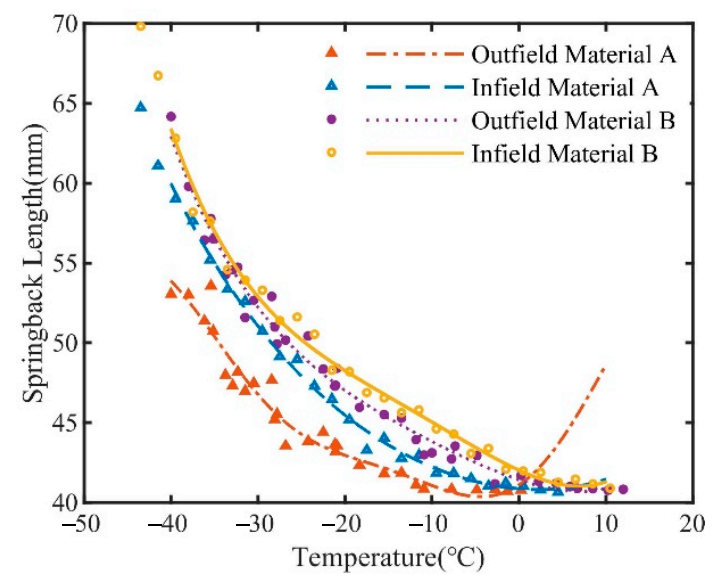

(e)

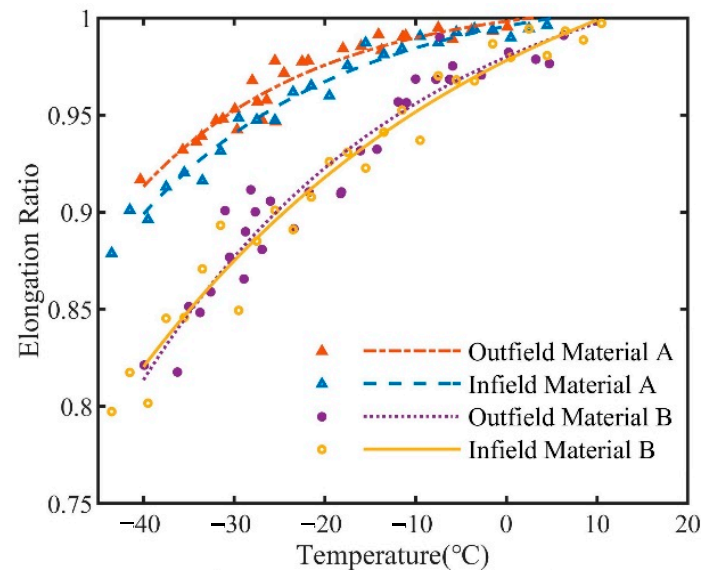

(d)

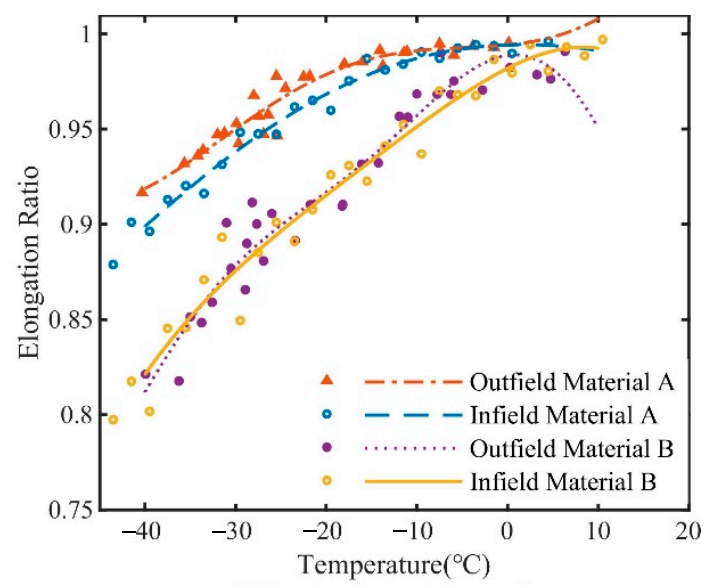

(f)

Figure 8. Fitting of the test results. (a) Polynomial fitting curves in springback test (b) Polynomial fitting curves in elongation test (c) Exponential fitting curves in springback test (d) Exponential fitting curves in elongation test (e) Fourier fitting curves in springback test (f) Fourier fitting curves in elongation test.

It can be seen from Table 4 and Figure 7 that all the methods are almost equivalent, with the exception of the elongation outfield test for material A, where the exponential fitting is the worst.

\subsection{Similarity Analysis of Infield and Outfield Tests}

Comparing the measured data of the infield and outfield low-temperature steadystate response of the two materials, this study found that differences existed in the lowtemperature hardening. In view of the different elastic responses of the two rubber sealing materials to the low-temperature infield and outfield, three fitting curves were then used to translate the infield test curves to study the similarity of the infield and outfield curves based on the existing outfield curves. The translation takes the translation $d T$ as the transformation parameter, and the goodness of fit of the curve derived from the infield and the data from the outfield as the transformation parameter. The similar transformation parameters of the translation transformation of the three fitting methods are shown in Table 5. The goodness of fit is shown in Table 6. 
Table 5. Fitting parameter of infield and outfield similarity transformation $d T$.

\begin{tabular}{ccccc}
\hline Fitting Type & A Springback & B Springback & A Elongation & B Elongation \\
\hline Polynomial fitting & 6.5365 & 1.273 & 3.927 & 0.57 \\
\hline Exponential fitting & 6.4853 & 1.3771 & 3.7818 & 0.4719 \\
\hline Fourier fitting & 6.5585 & 0.89 & 3.906 & 0.04976 \\
\hline
\end{tabular}

Table 6. Goodness of fit of infield and outfield similarity transformation $R^{2}$.

\begin{tabular}{ccccc}
\hline Fitting Type & A Springback & B Springback & A Elongation & B Elongation \\
\hline Polynomial fitting & 0.947 & 0.9746 & 0.92481 & 0.93142 \\
\hline Exponential fitting & 0.9378 & 0.9803 & 0.91336 & 0.9297 \\
\hline Fourier fitting & 0.94579 & 0.97416 & 0.92499 & 0.93074 \\
\hline
\end{tabular}

The infield and outfield translation transformation show desirable fitting results. Thus, the similarity of the infield and outfield curves can be considered good. Comparing the results of the infield and outfield transformations with the three fitting methods, this study found that polynomial fitting is equivalent to Fourier fitting in curve fitting, but that the goodness of fit of the outfield points is higher for the poor translation transformation of the infield test curve, and has poor goodness of fit and transformation of the exponential fitting.

A comparison of the two materials shows that the similarity of their infield and outfield curves is obvious, because the change of the material properties in the infield and outfield tests of the samples from the same material obeys the same change law (i.e., it hardens gradually as the temperature decreases), the points on the infield curve and the outfield curve correspond one by one.

\subsection{Similarity Calculation Method of Infield and Outfield Tests}

The test data of the infield and outfield low-temperature steady-state response show high elastic similarity of the infield and outfield specimens.

In order to make the derived curve keep the curve characteristics of the infield curve, the method of scaling translation, i.e., linear transformation, is selected to transform the curve when deriving the outfield-derived curve based on the infield curve. During the linear transformation, the new curve will not change the function relationship with the original curve or the function properties of the original curve.

When similar transformation is made to the curve of the infield test,

$$
T_{1}=k T+d T^{\prime}
$$

where $T$ is the temperature of the infield test, $T_{1}$ is the temperature of outfield transformation from the infield test, $k$ is the scaling ratio of the curve, and $d T^{\prime}$ is the translation parameter.

To obtain the derived outfield curve, the following procedures were conducted. First, select a low-temperature $\left(-25^{\circ} \mathrm{C}\right)$ outfield data sampling point $\mathrm{A}\left(T_{a}, L_{a}\right)$ and a hightemperature $\left(-5^{\circ} \mathrm{C}\right)$ outfield data sampling point $\mathrm{B}\left(T_{b}, L_{b}\right)$. Then, transform the infield fitting curve in the way of translation and scaling transformation to make the transformed curve pass through the sampling points. Suppose that the temperature dependence of the tensile value of the infield is

$$
L=F(T)
$$

For A and B,

$$
\begin{aligned}
& L_{a}=F\left(T_{a}^{\prime}\right) \\
& L_{b}=F\left(T_{b}^{\prime}\right)
\end{aligned}
$$


When $L_{a}$ and $L_{b}$ are known, $T_{a}^{\prime}$ and $T_{b}^{\prime}$ of the infield temperature in the corresponding range can be obtained, which are the infield temperature when the length of the test piece is $L_{a}$ and $L_{b}$ in the infield test, as shown in Figure 9.

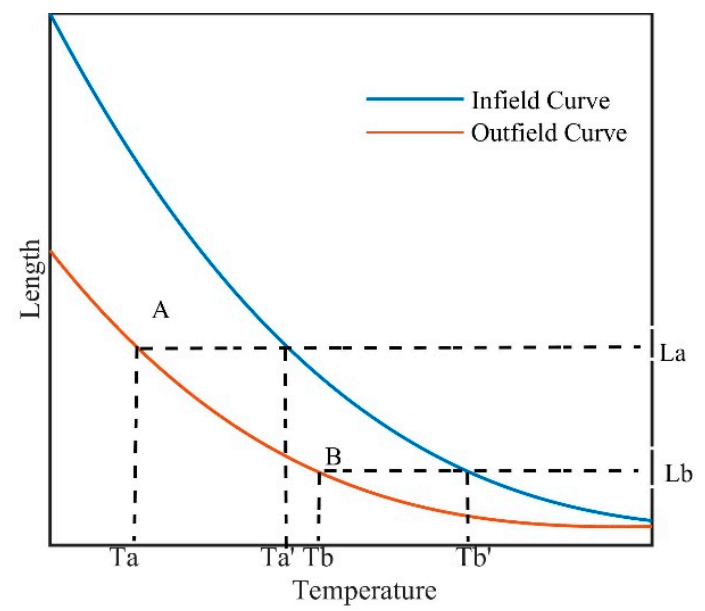

Figure 9. Transformation diagram.

Substituting Equations (12) and (13) into Equation (10) yields

$$
\begin{aligned}
& T_{a}=k T_{a}^{\prime}+d T^{\prime} \\
& T_{b}=k T_{b}^{\prime}+d T^{\prime}
\end{aligned}
$$

The scaling ratio $k$ and the translation parameter $d T^{\prime}$ are obtained by simultaneous solution.

By changing the temperature of the infield curve according to Equation (10), the derived curve of the low-temperature elastic properties of the rubber material in the outfield can be obtained, which leads to the similarity calculation method of the infield and outfield low-temperature test based on the translation and scaling transformation of the similar curve.

\subsection{Verification of Similarity Calculation Method for Infield and Outfield Tests}

In order to verify whether the outfield curve obtained by the similarity calculation method can fit the outfield test data well, the outfield curve obtained by the two-point translation and scaling transformation is verified by the test data obtained from the outfield sampling. The curve derived from the outfield is compared with the four-point interpolation curve and the polynomial fitting curve.

Among the data of the outfield test, the points with temperature of $0,-15,-25$, and $-35^{\circ} \mathrm{C}$ were selected to directly interpolate and fit the curve of material A. The interpolation curve of material A in the springback tests is as follows:

$$
L_{1}(T)=-0.00038049 T^{3}-0.00815475 T^{2}-0.09873783 T+40.80853008
$$

The interpolation curve of material A in the elongation tests is as follows:

$$
L_{2}(T)=-0.00000159 T^{3}-0.00002311 T^{2}-0.00057873 T+0.99521616
$$

In the outfield test data, the points with temperature of $10,-5,-20$, and $-35{ }^{\circ} \mathrm{C}$ were selected to directly interpolate and fit the curve of material $\mathrm{B}$. The sampling point of material $\mathrm{B}$ is different from that of material A, because material $\mathrm{B}$ also has low temperature hardening when it is higher than $0^{\circ} \mathrm{C}$, while material $\mathrm{A}$ has no hardening when it is higher than $0^{\circ} \mathrm{C}$. When comparing with four point interpolation and transformation, the sampling points with better fitting are selected according to the distribution interval and density 
of the sampling points. The interpolation curve of material A in the springback tests is as follows:

$$
L_{1}(T)=-0.00002860 T^{3}+0.00581235 T^{2}-0.17353707 T+41.96555913
$$

The interpolation curve of material B in the elongation test is as follows:

$$
L_{2}(T)=-0.00000213 T^{3}-0.00014557 T^{2}-0.00142622 T+0.98835368
$$

The outfield interpolation curve and outfield scatter are shown in Figure 10, and the goodness of fit is shown in Table 7.

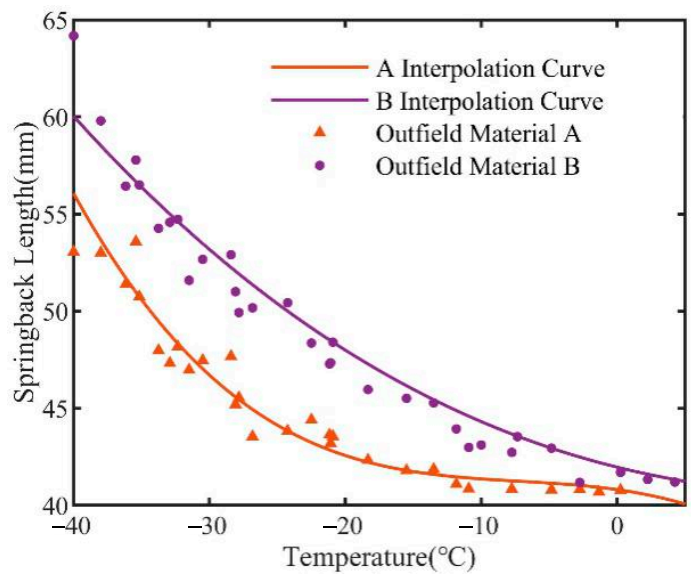

(a)

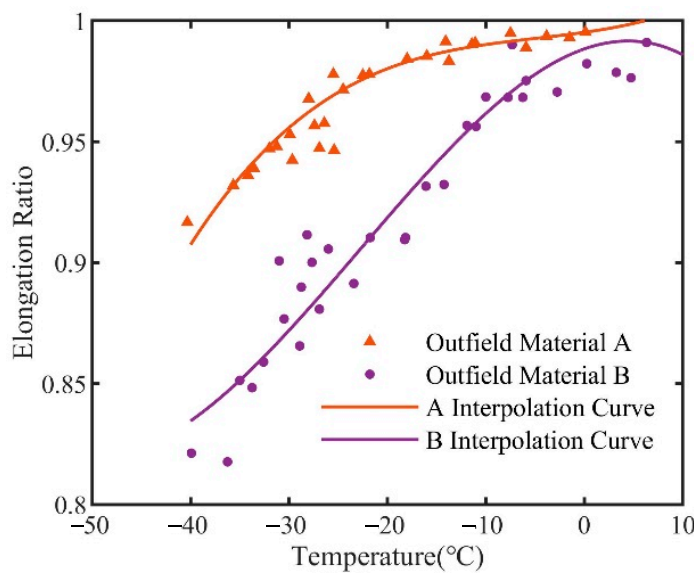

(b)

Figure 10. Interpolation curves. (a) Springback (b) Elongation.

Table 7. Goodness of fit of four-point sampling interpolation.

\begin{tabular}{ccccc}
\hline Fitting Type & A Springback & B Springback & A Elongation & B Elongation \\
\hline Goodness of fit $R^{2}$ & 0.9351 & 0.8764 & 0.8934 & 0.9242 \\
\hline
\end{tabular}

The similarity calculation method of the low-temperature tests based on the translation and scaling transformation of the similar curve was adopted, and the infield tests curve obtained by polynomial fitting method was used. Substituting formula (7) into formula (11) yields the transformation parameters and the outfield curve based on the polynomial infield fitting curve and outfield sampling point. The scaling ratio, translation parameter $d T^{\prime}$ and the goodness of fit $R^{2}$ are shown in Table 8, and the derived outfield curve is shown in Figure 11.

Table 8. Scaling translation transformation coefficient and goodness of fit.

\begin{tabular}{cccc}
\hline Fitting Type & $\boldsymbol{k}$ & $\boldsymbol{d} \boldsymbol{T}^{\prime}$ & $\boldsymbol{R}^{\mathbf{2}}$ \\
\hline A springback polynomial fitting & 0.986 & -7.719 & 0.9470 \\
\hline A elongation polynomial fitting & 1.117 & -0.375 & 0.9148 \\
\hline B springback polynomial fitting & 0.976 & -3.381 & 0.9562 \\
\hline B elongation polynomial fitting & 0.950 & -2.014 & 0.9323 \\
\hline
\end{tabular}




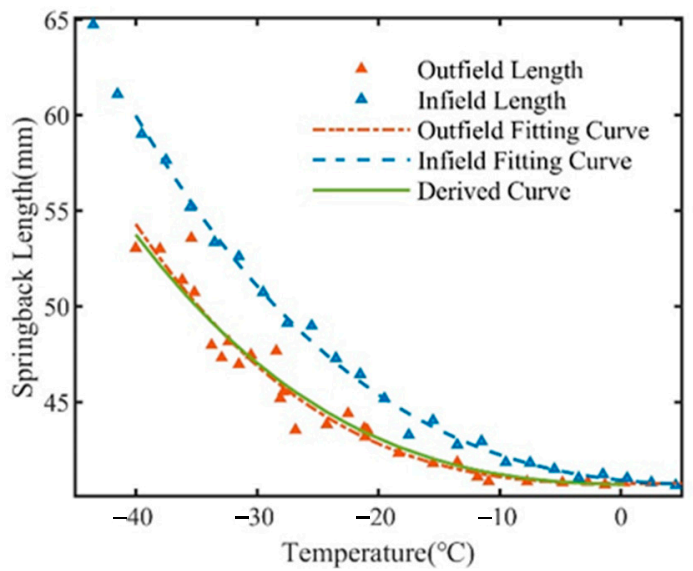

(a)

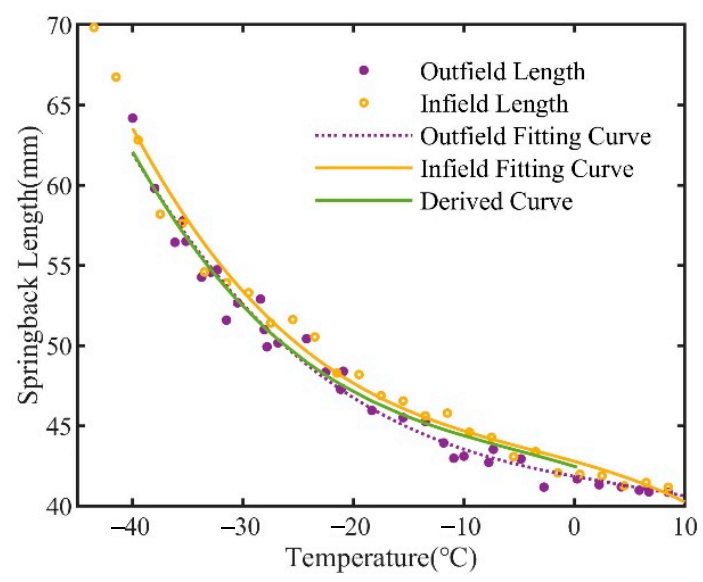

(c)

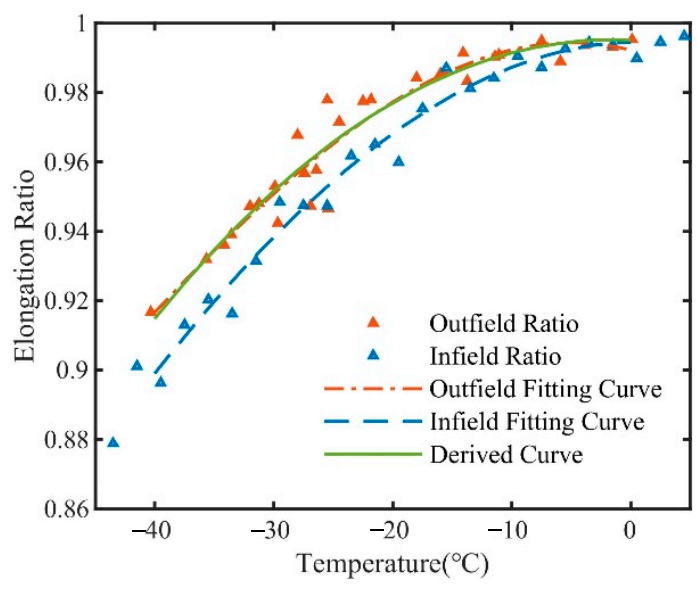

(b)

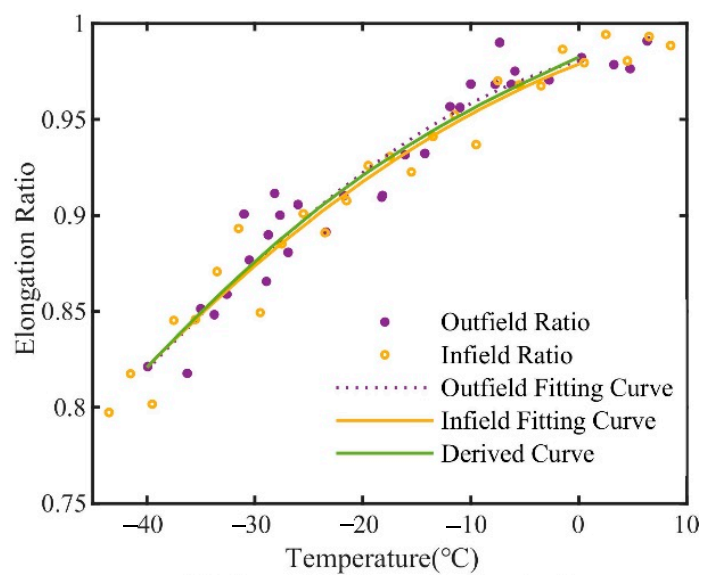

(d)

Figure 11. Derivation curve and fitting curve of polynomial fitting. (a) Material A springback derivation (b) Material A elongation derivation (c) Material B springback derivation (d) Material B elongation derivation.

Then the study compared the derived outfield curve obtained by scaling transformation with the similarity calculation method, four-point interpolation curve and outfield polynomial fitting curve in terms of the goodness of fit. The results are shown in Figure 12.

Next, the study compared the curve derived from the two-point translation scaling transformation obtained by the similarity calculation method, the four point interpolation curve and the outfield polynomial fitting curve in terms of the goodness of fit. The higher the goodness of fit, the closer the fitted curve is to the outfield test results. The comparison shows that the best fitting curve is the outfield polynomial fitting curve, that the second best is the curve derived from the two-point translation scaling transformation using the similarity calculation method, and that the worst is the four-point interpolation fitting curve. The fitting effect of the derived curve is better than that of the four-point interpolation curve, which is close to that of the outfield fitting curve. In other words, the fitting effect of the derived curve is closer to that of the outfield curve.

The curve fitting of the infield and outfield tests was optimized by the goodness of fit. The optimized curve does not pass most of the corresponding experimental points. In the process of interpolation, the interpolation curve must pass through the sampling point in the outfield, and at this time, the curve may be quite different from the corresponding data at other temperatures, so the goodness of fit of the curve is relatively low. For samples from the same material, the low-temperature elastic response of the infield and outfield environments obeys the performance law of the same material. By taking the samples 
from the outfield to obtain the transformation parameters for similar transformations, the derived curve does not change the function properties or the relations compared with the corresponding infield test curve, and the derived curve still obeys the material performance law similar to that of the infield curve. Therefore, the derived curve has a high goodness of fit to the outfield test data.

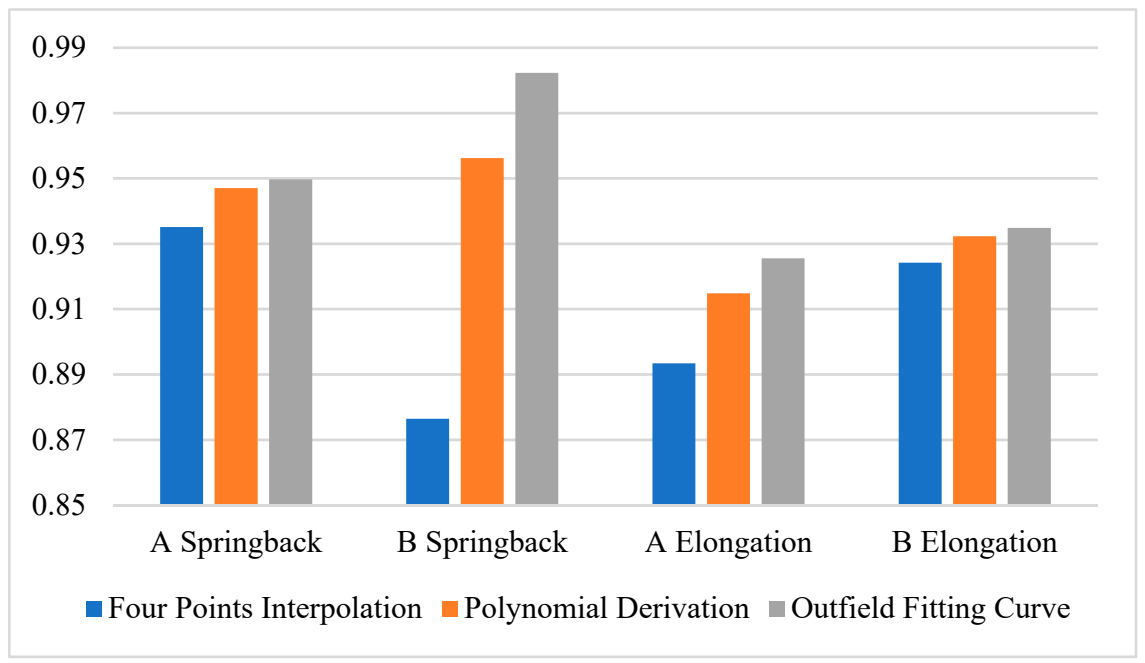

Figure 12. Comparison of goodness of fit between four-point interpolation curve, transformation derived curve and outfield fitting curve.

The similarity calculation method based on the translation and scaling transformation of the similar curve is applied to the translation and scaling transformation of two points in the other two fitting methods, i.e., substituting Equations (8) and (9) into Equation (11). Based on the infield fitting curve and outfield sampling point, the transformation parameters and outfield curve are obtained. The scaling ratio, translation parameter $d T^{\prime}$ and the goodness of fit $R^{2}$ are shown in Table 9, and the derived outfield curve is shown in Figures 13 and 14.

Table 9. Scaling translation coefficient and goodness of fit based on exponential and Fourier fittings.

\begin{tabular}{cccc}
\hline Fitting Type & $\boldsymbol{k}$ & $\boldsymbol{d} \boldsymbol{T}^{\prime}$ & $\boldsymbol{R}^{\mathbf{2}}$ \\
\hline A springback exponential fitting & 1.091 & -4.398 & 0.9256 \\
\hline A elongation exponential fitting & 1.072 & -1.475 & 0.9042 \\
\hline B springback exponential fitting & 1.058 & -0.644 & 0.9675 \\
\hline B elongation exponential fitting & 0.938 & -2.553 & 0.9295 \\
\hline A springback Fourier fitting & 1.038 & -6.255 & 0.9425 \\
\hline A elongation Fourier fitting & 1.113 & -0.556 & 0.9164 \\
\hline B springback Fourier fitting & 1.212 & 3.279 & 0.9590 \\
\hline B elongation Fourier fitting & 0.950 & -1.997 & 0.9323 \\
\hline
\end{tabular}




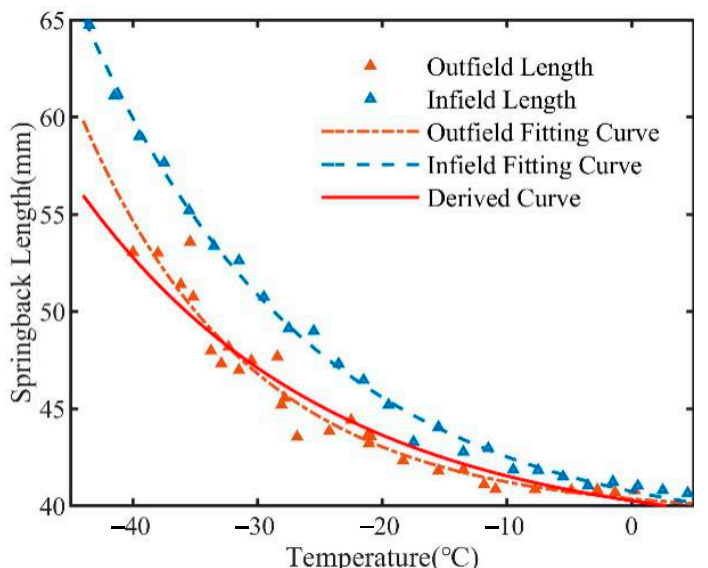

(a)

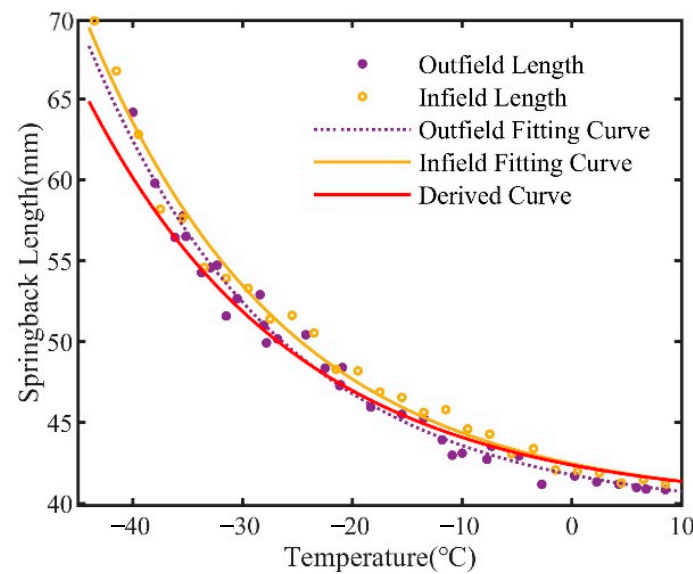

(c)

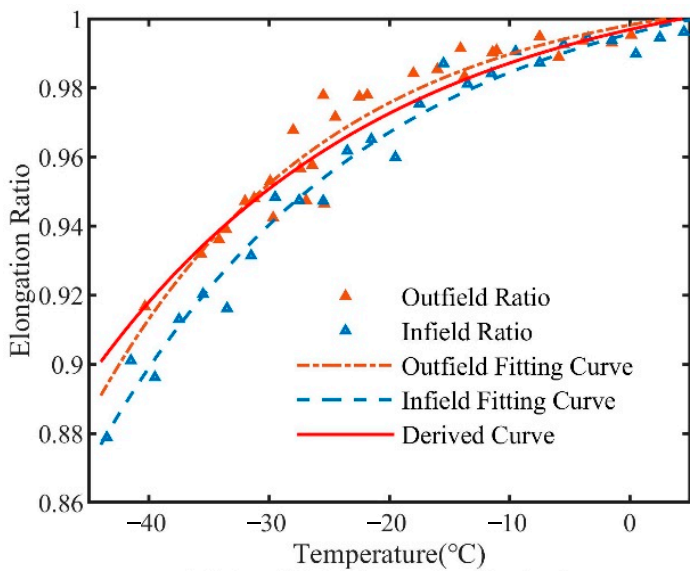

(b)

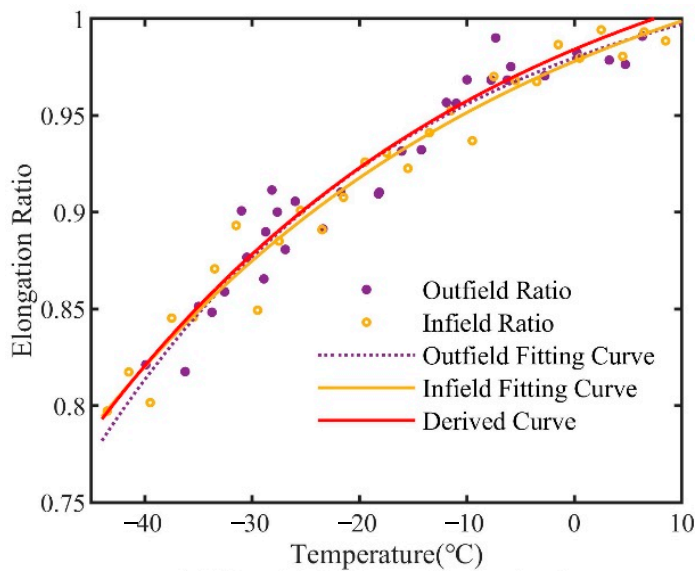

(d)

Figure 13. Derivation curve and fitting curve of exponential fitting. (a) Material A springback derivation (b) Material A elongation derivation (c) Material B springback derivation (d) Material B elongation derivation.

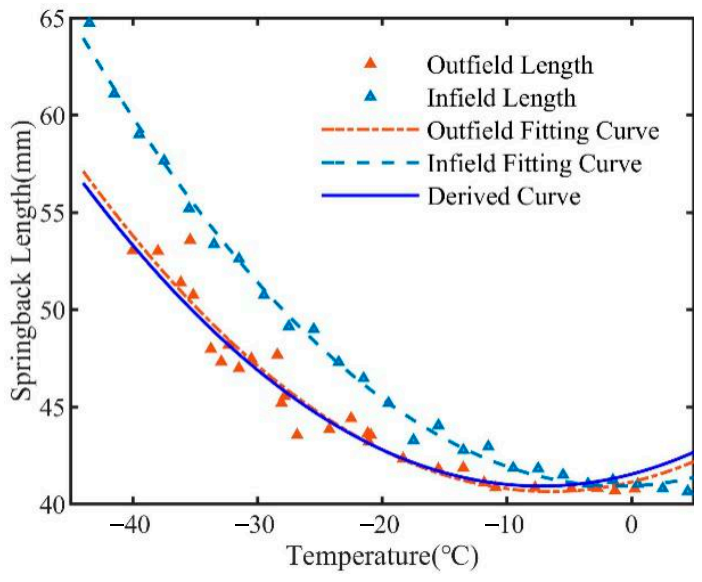

(a)

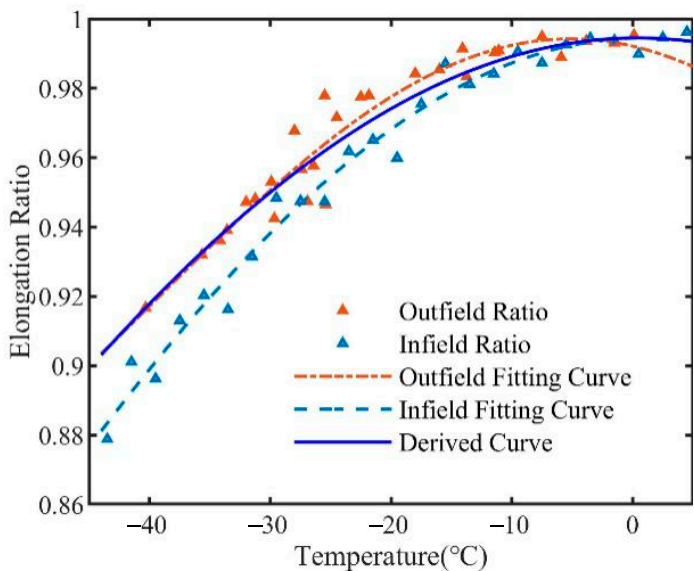

(b)

Figure 14. Cont. 


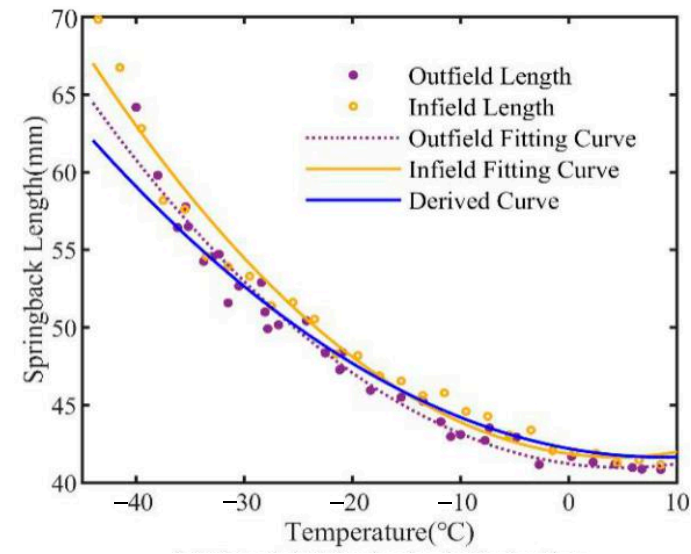

(c)

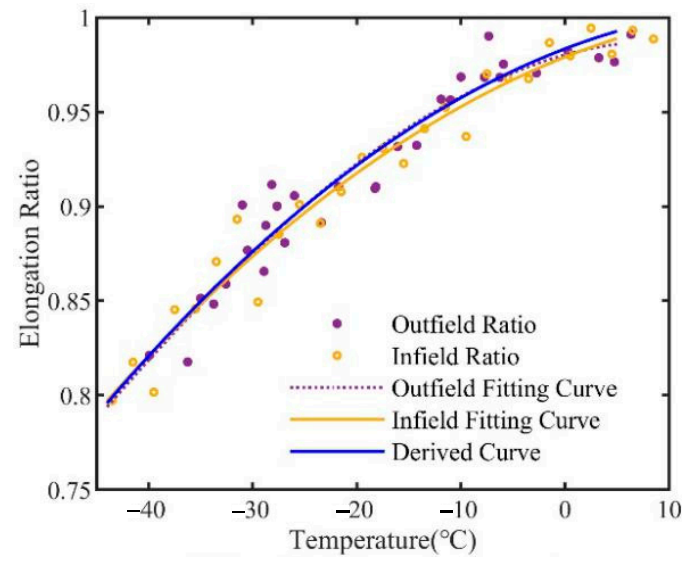

(d)

Figure 14. Derivation curve and fitting curve of Fourier fitting. (a) Material A springback Derivation (b) Material A elongation Derivation (c) Material B springback derivation (d) Material B elongation derivation.

The goodness of fit of the derived curve obtained by the similarity calculation method under the three fitting forms is compared with that of the corresponding outfield fitting curves. The results are shown in Figure 15.

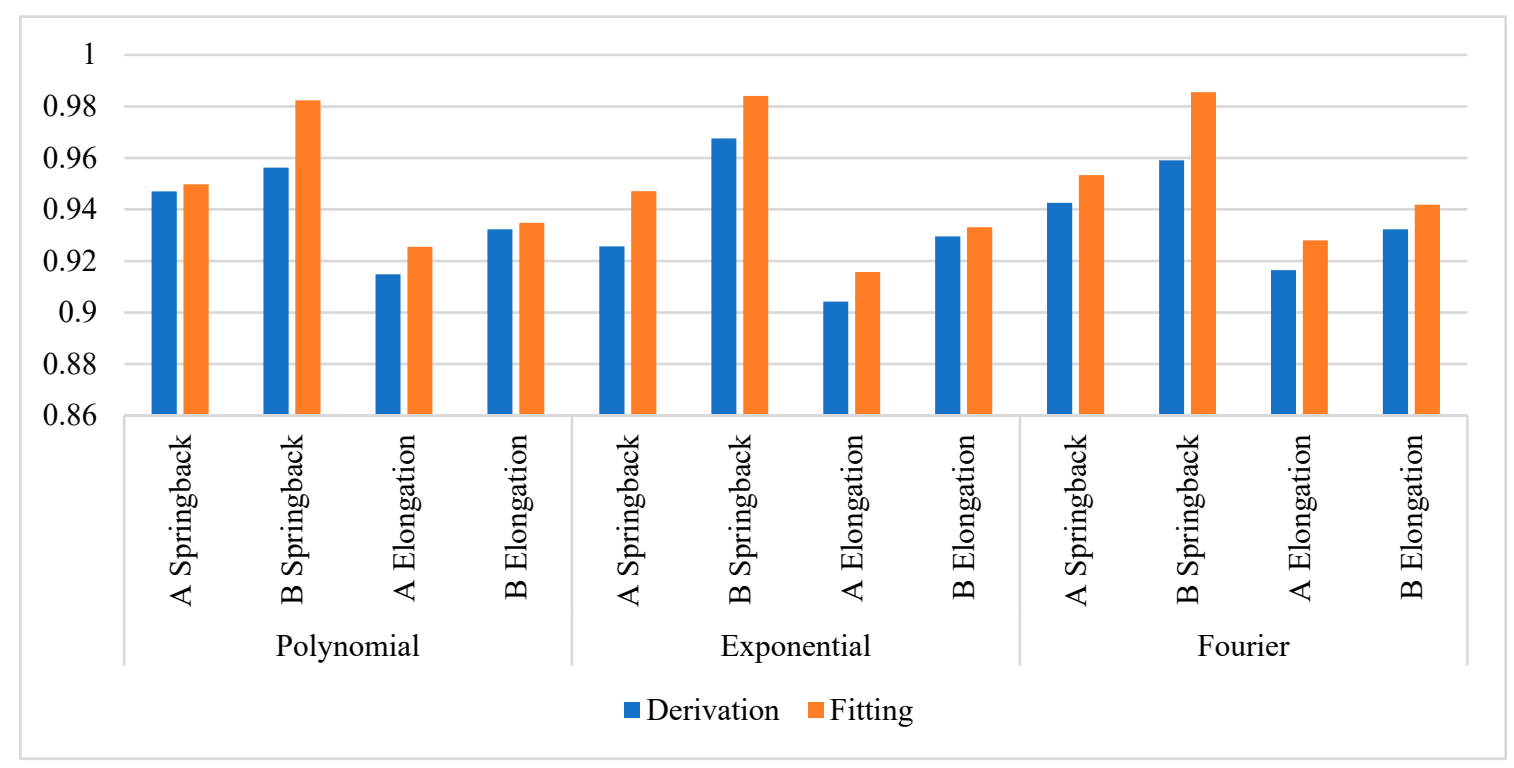

Figure 15. Goodness of fit of derived curve and fitting curve.

From Figure 15, it can be found that for the three fitting methods and two materials, the goodness of fit of the derived curve obtained by the similarity calculation method is close to that of the corresponding outfield fitting curve. For any kind of material, when its performance in the environmental test chamber is similar to that in the outfield environment (as shown in Figure 9), that is, when the main influencing factor of the material's performance in the outfield environment is the same as that in the infield environment, and there are similar performance changes, this method can be applied. This similarity calculation method of the translation and scaling transformation can be used for different materials and multiple fitting methods, with good feasibility and generalizability.

Through the verification of the outfield point data, this study obtains an effective similarity calculation method based on the translation and scaling transformation of the similar curve. Based on the known curve of the infield low-temperature steady-state response of the aircraft rubber sealing materials, two temperature sampling points in 
the outfield which are far away from each other are taken to obtain the outfield lowtemperature performance of the material and judge whether there is any difference in the infield and outfield performance of the material. Based on the similarity of the infield and outfield properties of the material, the curve is obtained by the curve translation and scaling transformation. This method has fewer sampling points in the outfield tests with good curve fitting results. Hence, it can be applied to different kinds of materials and methods due to its good feasibility and generalization ability. In the design and research of the key components of the aircraft, the outfield performance of the material can be easily derived using the similarity calculation method proposed here. This method can also be used as a basic technical support and reference in the selection of the low temperature materials for the key components of aircraft and the design of low temperature environment simulation tests.

\section{Conclusions}

(1) The springback tests and elongation tests of the rubber sealing materials were carried out from -40 to $10^{\circ} \mathrm{C}$. The rubber sample hardens at low temperature. When the temperature continues to decrease, the material will undergo glass transition and lose its elasticity. Moreover, the difference between the infield and outfield environments of material A is large, with hardening being more obvious in the infield test environment, but the difference between the infield and outfield environments of material B is small. The reason for the difference may be the factors such as sunshine and air flow in the outfield environment. The sensitivity of the material to the complex outfield environment is different, and the material $\mathrm{A}$ is more sensitive.

(2) Based on the test results of the infield and outfield environment, the steady-state response curves of the two materials in the tests were obtained by different fitting models. Different fitting methods were selected to analyze the similarity between infield test curve and outfield test curve based on translation. The infield and outfield test curves have good similarity; the low-temperature elastic response of the samples from the same material obeys the same material performance law.

(3) A similarity calculation method for low-temperature test infield and outfield is proposed. Two isolate temperature sampling points of the known curve in the outfield are taken to judge whether there is a difference in the infield and outfield environments. The outfield-derived curve was obtained by the curve translation and scaling transformation.

(4) The interpolation curve, outfield polynomial fitting curve and outfield-derived curve obtained were compared. The goodness of fit of the curve derived by the similarity calculation method is higher. The derived curve obtained by the similarity calculation method and the corresponding outfield fitting curve were also compared. The goodness of the derived curve obtained by using the similarity calculation method is close to that of the outfield fitting curve. The similarity calculation method has a smaller error, and thus can be used in many materials and different fitting methods.

(5) The similarity calculation method based on the translation and scaling transformation of the similarity curve in the infield and outfield low-temperature tests can conveniently deduce the outfield performance of the material. This method shows feasibility and generalizability. This method can also be used in the low-temperature performance testing and research of rubber materials and components.

Author Contributions: Formal analysis, R.G.; Funding acquisition, Y.Z. (Yongjie Zhang); Investigation, Y.Z. (Yongjie Zhang) and K.L.; Methodology, Y.Z. (Yongjie Zhang); Project administration, Y.Z. (Yongjie Zhang); Software, Y.Z. (Yunhui Zhang); Validation, Y.Z. (Yunhui Zhang). All authors have read and agreed to the published version of the manuscript.

Funding: The author(s) disclosed receipt of the following financial support for the research, authorship, and/or publication of this article: This work was supported by the National Natural Science Foundation of China (Grant Nos. 11972301, 11201375, 11972300).

Institutional Review Board Statement: Not applicable. 
Informed Consent Statement: Not applicable.

Data Availability Statement: All data, models, and code generated or used during the study appear in the submitted article.

Conflicts of Interest: The authors declare that no conflict of interest.

\section{References}

1. Wood, L.A.; Bekkedahl, N. Crystallization of Unvulcanized Rubber at Different Temperatures. J. Appl. Phys. 1946, 17, 362-375. [CrossRef]

2. Jaunich, M.; Stark, W.; Wolff, D. A new method to evaluate the low temperature function of rubber sealing materials. Polym. Test. 2010, 29, 815-823. [CrossRef]

3. GBT 528-2009 Rubber, Vulcanized or Thermoplastic_Determination of Tensile Stress-Strain Properties; Standardization Administration of China: Beijing, China, 2009.

4. HGT 3867-2008 Vulcanized Rubber-Determination of Coefficient of Low Temperature Resistance at Extention; Standardization Administration of China: Beijing, China, 2008.

5. Kunz, S.C.; Beaumont, P.W.R. Low-temperature behaviour of epoxy-rubber particulate composites. J. Mater. Sci. 1981, 16, 3141-3152. [CrossRef]

6. Song, Y.H.; Liu, J.; Wei, B.R. Low Temperature Properties of Silicone Rubber. Spec. Purp. Rubber Prod. 1999, $20,10-15$.

7. Ding, Z.P.; Mu, L.H.; Bu, J.L.; Huang, Y.; Zeng, J. Stiffness prediction of rubber springs at lower temperature. J. Vib. Shock 2017, 36, 66-70.

8. Chen, P.; Wang, X.F.; Song, C.J. Study on Crystallization Property of Isoprene Rubber at Low Temperature Compression Strain. Spec. Purp. Rubber Prod. 2011, 32, 22-25.

9. Zhang, W.; Zhang, P.T.; Xiao, J.B. Study on Low Temperature Performance of Common Rubbers. Spec. Purp. Rubber Prod. 2019, 40, 27-29.

10. You, S.Q.; Liu, B.; Lou, Y.L. Low-temperature effect on deformation behavior of laminated rubber isolators. J. Northeast. Univ. 2005, 26, 297-299.

11. Mu, L.H.; Ding, Z.P.; Huang, Y.; Zeng, J.; Pu, J. The Method of Stiffness Prediction of Rubber Elastic Elements in Low Temperature. J. Hunan Univ. Technol. 2016, 30, 11-16.

12. Ren, J.S.; Huang, X. Experimental Study of Natural Rubber Mechanical Property in Variable Temperature Fields. J. Exp. Mech. 2007, 22, 612-616.

13. Yu, H.Q.; Liu, X.H. Study on shear properties of low temperature modified nature rubber. J. Solid Rocket Technol. 2006, 29, 222-224.

14. Cunneen, J.I.; Shipley, F.W. Improvement of the Low Temperature Properties of Natural Rubber by Reaction with Thiol Acids in Solution and in Latex. J. Polym. Sci. 1959, 36, 77-90. [CrossRef]

15. Wang, F.S.; Gao, X.W.; Cao, J.Y.; Liu, Z.G. Research on low temperature resistant rubber damping elements for rail vehicles. Roll. Stock 2012, 50, 22-25.

16. Feng, L.Z.; Lai, L.Q.; Fan, H.D.; Zheng-Tao, S.U.; Liu, J. A Study on Low Temperature Resistance of Methyl Styrene-butadiene Rubber. J. New Ind. 2019, 9, 78-81.

17. Fuller, K.N.G.; Gough, J.; Thomas, A.G. The Effect of Low-Temperature Crystallization on the Mechanical Behavior of Rubber. J. Polym. Sci. Part B Polym. Phys. 2004, 42, 2181-2190. [CrossRef]

18. Khattak, A.; Iqbal, M.; Amin, M. Aging analysis of high voltage silicone rubber/silica nanocomposites under accelerated weathering conditions. Sci. Eng. Compos. Mater. 2016, 24. [CrossRef]

19. Liu, X.; Zhao, J.; Yang, R.; Iervolino, R.; Barbera, S. Effect of lubricating oil on thermal aging of nitrile rubber. Polym. Degrad. Stab. 2018, 151, 136-143. [CrossRef]

20. Dahiya, R.C.; Gurland, J. Goodness of fit tests for the gamma and exponential distributions. Technometrics 1972, 14, 791-801. [CrossRef]

21. Schlesinger, J. Fit to experimental data with exponential functions using the fast Fourier transform. Nucl. Instrum. Methods 1973, 106, 503-508. [CrossRef]

22. Gálvez, A.; Iglesias, A. A new iterative mutually coupled hybrid GA-PSO approach for curve fitting in manufacturing. Appl. Soft Comput. 2013, 13, 1491-1504. [CrossRef]

23. Zhou, B.; Ye, H. A study of polynomial fit-based methods for qualitative trend analysis. J. Process Control 2016, $37,21-33$. [CrossRef] 